Jing Qin

Ping Liu

Gang Wu

Research Center for Eco-

Environmental Sciences, Chinese

Academy of Sciences, Beijing, P. R.

China
Research Article

\section{Variations in Phosphorus Speciation in Response to Simulated Riparian Zone Enhancement with Red Mud to Treat Reclaimed Water}

Variations in phosphorus speciation in two sets of simulated riparian zones with and without Perennial ryegrass were compared. Each set consisted of four units, each measuring $700 \mathrm{~mm} \times 200 \mathrm{~mm} \times 200 \mathrm{~mm}$, which were enhanced with $0,2.5,5$, and $7.5 \%$ red mud $(\mathrm{RM})$ by weight. The levels of total phosphorus (TP), total dissolved phosphorus (TDP), soluble reactive phosphorus (SRP) in the effluent were analyzed, and phosphorus fractionation in the media were also determined after the systems had been operational for 3 months. The results showed that the unit received $2.5 \% \mathrm{RM}$ had the highest rate of phosphorus removal, including TP, TDP, SRP, particulate phosphorus (PP), and dissolved organic phosphorus (DOP) were present at the average concentrations of $0.17,0.10,0.07,0.08$, and $0.03 \mathrm{mg} / \mathrm{L}$ in the effluent. Sequential phosphorus fractionation showed that calcium-bound phosphorus (Ca-P) was the major component, indicating that the addition of RM induced aluminum/iron-bound phosphorus $(\mathrm{Al} / \mathrm{Fe}-\mathrm{P})$, which was intensely bioactive, to form intractable $\mathrm{Ca}-\mathrm{P}$, which further inhibited the release of phosphorus from the media. However, the presence of P. ryegrass had little effect on the removal of phosphorus. Therefore, RM, when used directly in riparian zones at a suitable concentration, is a novel and low cost additive material that can be used to remove phosphorus from reclaimed water.

Keywords: Phosphorus speciation; Reclaimed water; Red mud; Simulated riparian zone

Received: December 1, 2011; revised: December 30, 2011; accepted: January 13, 2012

DOI: $10.1002 /$ clen.201100633

\section{Introduction}

Red mud (RM), which is generally classified as a solid waste, is generated from the production of alumina by the caustic digestion of bauxite ores [1]. RM, which has a large specific surface area and a homogeneous particle-size distribution, contains $\mathrm{Ca}, \mathrm{Fe}$, and $\mathrm{Al}$ oxides and other minor constituents $[2,3]$. It is usually directly disposed in deposit areas or dumped into the sea, which can result in not only the waste of this resource but also environmental pollution [1]. Recently, some studies have reported various applications for RM, including the removal of nitrates and phosphates, soil remediation at mines, metal recovery [4-6], etc. However, RM is still regarded as a hazardous environmental pollutant due to its highly alkaline properties and high concentrations of various chemical substances [3]. As a consequence, appropriate pretreatment of RM is necessary before practical use [2].

Correspondence: Professor P. Liu, Research Center for EcoEnvironmental Sciences, Chinese Academy of Sciences, Beijing 100085, P. R. China

E-mail: liuping@rcees.ac.cn

Abbreviations: Al/Fe-P, aluminum/iron-bound phosphorus; Ca-P, calcium-bound phosphorus; DOP, dissolved organic phosphorus; Ex-P exchangeable phosphorus; Org-P, organic-bound phosphorus; PP, particulate phosphorus; Res-P, residual phosphorus; RM, red mud; SRP, soluble reactive phosphorus; TDP, total dissolved phosphorus; TP, total phosphorus
Riparian zones have been widely used for reducing phosphorus pollution due to their low cost, convenient operation, and easy maintenance [7-9]. Adsorption and precipitation of the media is considered to be one of the most useful removal processes of phosphorus from a column of water in riparian zones [10, 11]. Different forms of phosphorus in wastewater, such as soluble reactive phosphorus (SRP), organic-bound phosphorus (Org-P), and particulate phosphorus (PP), and their dynamics have been reported to affect the efficiency of phosphorus removal [12]. However, there are few reports on the use of riparian zones to remove phosphorus from reclaimed water, which generally has a lower phosphorus load. In addition, there are few studies that have focused on variations in phosphorus speciation.

Therefore, a simulated riparian zone was constructed, which was enhanced with different additions of RM in order to treat reclaimed water. The aims of this study were as follows: (1) to investigate the role of RM on the efficiency of phosphorus species removal; (2) to analyze the phosphorus fractionations present in the media; and (3) to identify the effects of plants on phosphorus removal.

\section{Materials and methods}

\subsection{Simulated riparian zone}

Two sets of simulated riparian zones were constructed, including one of which grew $P$. ryegrass (noted as V), while the other set, as the 


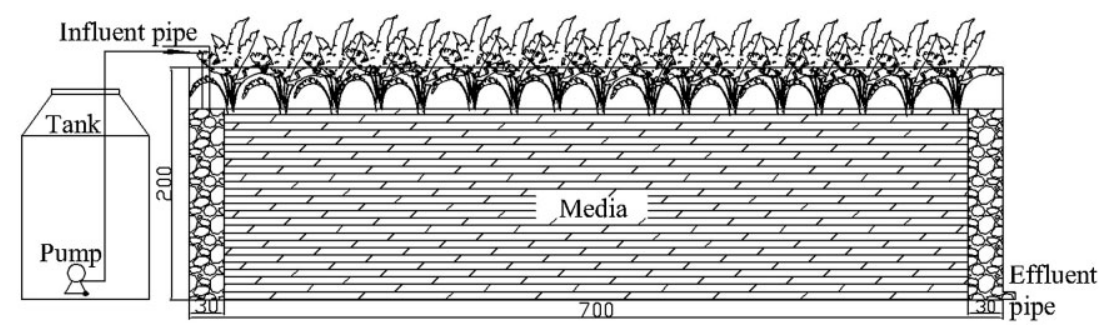

Figure 1. Schematic description of the simulated riparian zone model.

control (noted as C), did not grow any type of grass. Each set contained four small units of polyvinyl chloride (PVC) measuring $700 \mathrm{~mm} \times 200 \mathrm{~mm} \times 200 \mathrm{~mm}$ (Fig. 1). Each unit was filled with a mixture of RM and soil as the medium after homogeneous mixing. Due to its strong alkalinity, the $\mathrm{pH}$ of RM ranges from 11 to 12 , which declines the efficiency of the removal of phosphorus [3]. Therefore, the addition ratios of RM (\% wt) in the media were set at 0, 2.5, 5, and $7.5 \%$, which were recorded as $1-4$, correspondingly. Thus, the four units in the set with $P$. ryegrass were noted as V1-V4, and the units in the control were marked as $\mathrm{C1}-\mathrm{C} 4$, respectively. Each unit was composed of three parts: the first $30 \mathrm{~mm}$ of length was composed of coarse gravel (10-20 $\mathrm{mm}$ in diameter); the following $640 \mathrm{~mm}$ of length was composed of RM and soil (0-4 mm in diameter); and the final $30 \mathrm{~mm}$ of length was composed of coarse gravel $(10-20 \mathrm{~mm}$ in diameter).

\subsection{Artificial reclaimed water}

The concentration of total phosphorus (TP) in reclaimed water from sewage plants in China is about $1 \mathrm{mg} / \mathrm{L}$. In order to stabilize the quality of the influent, artificial reclaimed water was used in the present study. Phosphorus was obtained by adding $\mathrm{KH}_{2} \mathrm{PO}_{4}$ and $\mathrm{K}_{2} \mathrm{HPO}_{4} \quad(>98 \%$ pure $)$ to running water. $\mathrm{Al}_{2} \mathrm{O}_{3}$, $\left(\mathrm{NH}_{2}\right)_{2} \mathrm{CO}, \mathrm{H}_{3} \mathrm{BO}_{3}, \mathrm{NH}_{4} \mathrm{NO}_{3}, \mathrm{CaCl}_{2}, \mathrm{CuSO}_{4}, \quad \mathrm{MgCl}_{2}, \quad \mathrm{FeCl}_{2}$, $\left(\mathrm{NH}_{4}\right)_{6} \mathrm{Mo}_{7} \mathrm{O}_{24}$, and $\mathrm{C}_{6} \mathrm{H}_{12} \mathrm{O}_{6}(>98 \%$ pure) were used to provide carbon, nitrogen, and various microelements. Thus, artificial reclaimed water was synthesized that included (in $\mathrm{mg} / \mathrm{L}$ ) $1.2 \mathrm{P}, 70 \mathrm{COD}, 8 \mathrm{NH}_{4}^{+}-\mathrm{N}$, $9 \mathrm{NO}_{3}^{-}-\mathrm{N}$, and $12 \mathrm{TN}$. The artificial influent was delivered to the riparian zone after $P$. ryegrass had already vigorously grown. The systems were operational for 3 months from July 30 to October 30. During this time, the simulated systems were fed with the artificial reclaimed water once every 2 days, and the hydraulic retention time (HRT) was maintained at about $2 \mathrm{~h}$.

\subsection{Monitoring methods}

Effluent samples were analyzed for $\mathrm{pH}$, TP, total dissolved phosphorus (TDP), and SRP. The $\mathrm{pH}$ was directly measured using a DELTA320 pH meter. TP, TDP, and SRP were determined according to the method described by SEPAC [13]. Based on the concentrations of TP, TDP, and SRP measured in the effluent, the concentrations of $\mathrm{PP}$ and dissolved organic phosphorus (DOP) could be derived using the equations $\mathrm{PP}=\mathrm{TP}-\mathrm{TDP}$ and $\mathrm{DOP}=\mathrm{TDP}-\mathrm{SRP}$, respectively. The surface features and chemical compositions of the RM and soil were examined by scanning electron microscopy (SEM) and electron dispersive spectrometry (EDS) using an Hitachi S-3000N with an EDAX Genesis XM4. The $\mathrm{HClO}_{4}-\mathrm{H}_{2} \mathrm{SO}_{4}$ digestion method was used to determine the concentration of TP in each media sample [14]. The phosphorus fractions were extracted from each media sample according to the previous procedures [15-17], and consisted of exchangeable phosphorus (Ex-P), aluminum/iron-bound phosphorus (Al/Fe-P), Org-P, calcium-bound phosphorus (Ca-P), and residual phosphorus (Res-P).

\subsection{Data analysis}

Variations in the amount of phosphorus speciation in the effluent were analyzed by one-way ANOVA using SPSS 13.0 software. The different addition ratios of RM were used as the principal factor and phosphorus speciation was used as the dependent variable. The means were calculated to avoid pseudo-replication, as each addition ratios was assumed to be independent. The significance level was set at $5 \%$. CANOCO software for Windows 4.5 was used to analyze the role of the plants on the removal of phosphorus from the reclaimed water. Log transformations of the data were used to minimize analytical errors. Detrended correspondence analysis (DCA) was conducted on data with different addition ratios that were obtained from RM systems both with and without $P$. ryegrass in order to determine the length of the gradient along axis 1 . The results of the DCA analysis show that the simulated riparian zones were linear, regardless of the different addition ratios of RM, and all of the values obtained using the lengths of the gradients along axis 1 were $<3$. Therefore, ordination was performed using principal component analysis (PCA).

\section{Results and discussion}

\subsection{Chemical properties of the unused media}

The results of the SEM and EDS analysis of the RM and soil are shown in Fig. 2, which indicate that the surface structure and elemental compositions of these two substances are quite different. In comparison with the surface structure of soil, RM has not only a large proportion of voids that are evenly distributed, but also a fine particle size. In RM and soil, oxygen is the predominant element, accounting for 33.99 and $30.38 \%$ of the total elemental contents by weight, respectively. Calcium is the second most predominant element in RM, accounting for $26.62 \%$ of its weight, whereas, soil has only $2.53 \%$ calcium. Iron is the third most dominant element in $\mathrm{RM}$, accounting for $10.26 \%$ of the total elements, whereas, iron accounts for just $5.49 \%$ of the soil content. Different concentrations of various chemical elements in RM and soil are apt to induce different effects on the removal of phosphorus when used to treat reclaimed water in riparian zones.

The $\mathrm{pH}$ of the media has a great effect on the removal of phosphorus from reclaimed water [18]. The $\mathrm{pH}$ differed among the simulated riparian zones due to the addition of different ratios of RM to the media (Fig. 3). The pH values of the simulated systems increased as the addition ratio of $\mathrm{RM}$ in the media increased. The lowest $\mathrm{pH}$ value was found in $V 1$, with an average $\mathrm{pH}$ of 8.91 , whereas, the 

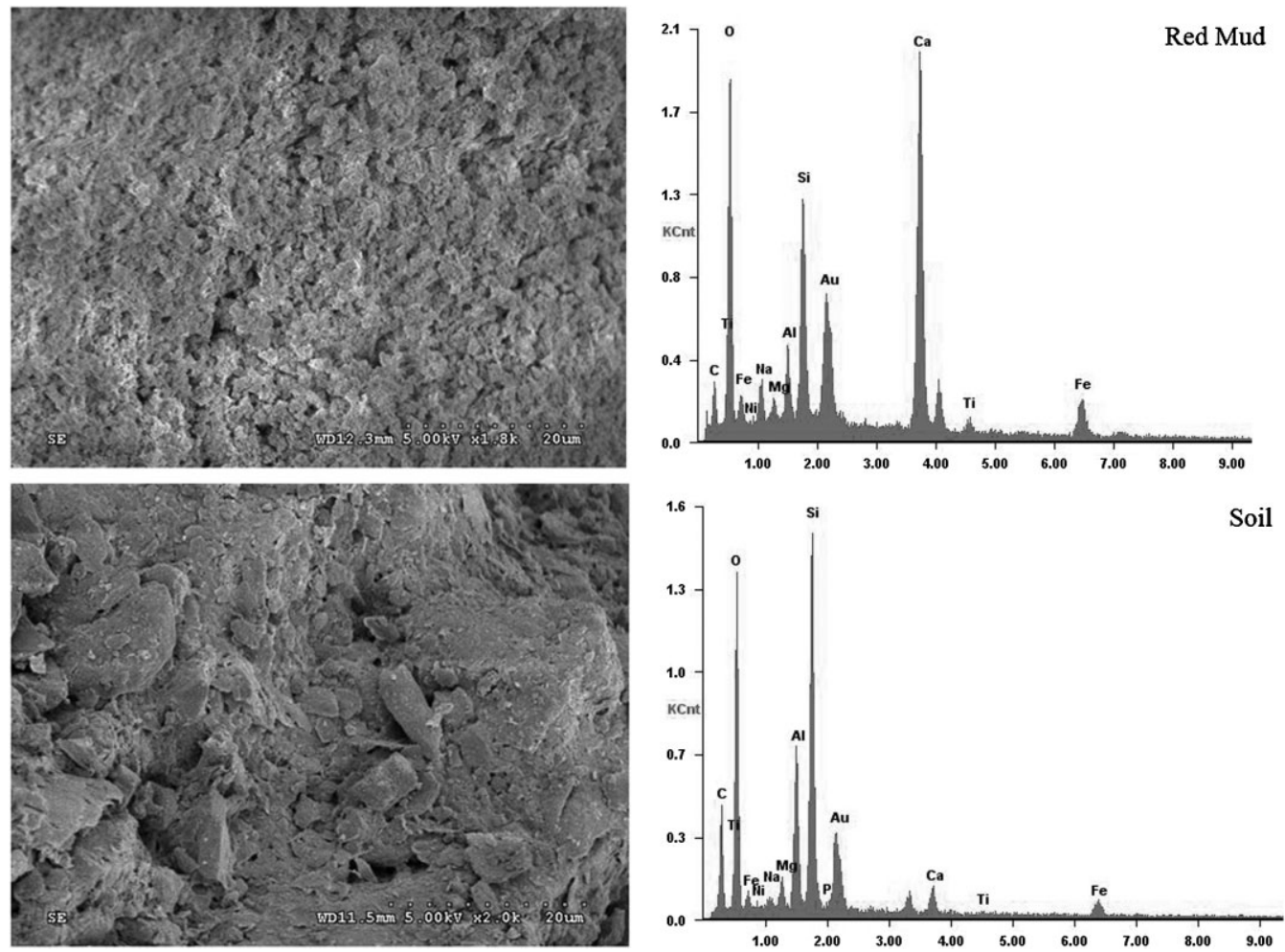

Figure 2. SEM images and EDS surface composition of soil and red mud.

highest appeared in V4, which had an average $\mathrm{pH}$ of 9.55. Therefore, the different addition ratios had an extremely significant effect on the $\mathrm{pH}(\mathrm{F}[\mathrm{d} f=3]=90.97 ; p<0.01)$. In situations where the $\mathrm{pH}$ ranges from 8.91 to 9.55 , calcium and magnesium ions play a critical role in the removal of phosphorus [19]. In addition, the forms of phosphorus that are present in a solution are closely related to $\mathrm{pH}$. When the $\mathrm{pH}$ is $>7.2$, most phosphorus tends to be present in the forms of $\mathrm{HPO}_{4}^{2-}$ and $\mathrm{PO}_{4}^{3-}$, whereas, $\mathrm{pH}<7.2, \mathrm{H}_{2} \mathrm{PO}_{4}^{-}$is the predominant form of phosphorus in solution [20]. Moreover, too high of a $\mathrm{pH}$ may have a detrimental effect on the growth of plants and reduce the biological activities of microorganisms, which would indirectly lower the removal efficiency of phosphorus [21].

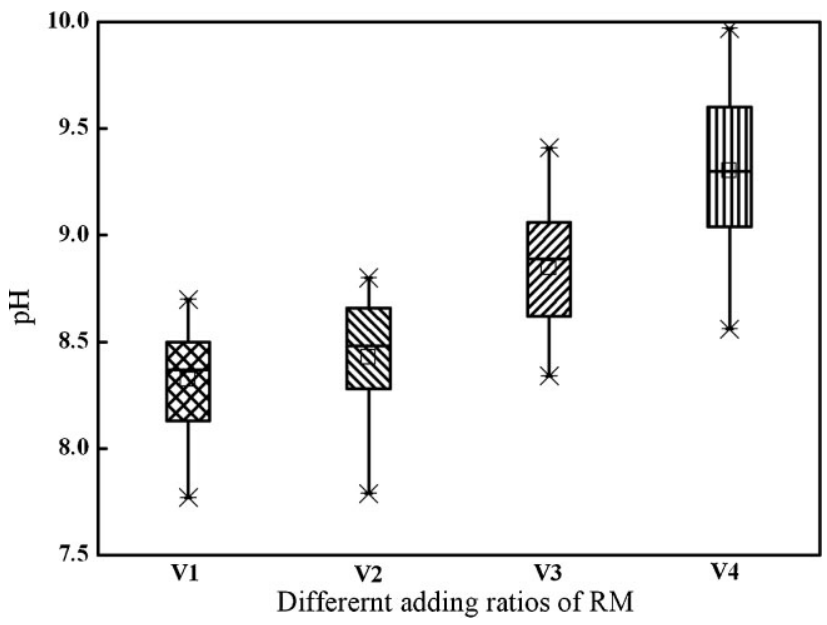

Figure 3. Variations in the $\mathrm{pH}$ values of the effluent collected from simulated riparian zones with $P$. ryegrass.

\subsection{Variations in phosphorus speciation in the effluent}

The concentration of various phosphorus species versus operation time is shown in Fig. 4, which shows great variability due to the different addition ratios of RM that were used in the media. The mean concentration of TP in the effluent was the lowest in V2, which was maintained at $0.17 \mathrm{mg} / \mathrm{L}$, while the highest was measured in $V 4$, which had an average concentration of $0.70 \mathrm{mg} / \mathrm{L}$. The mean concentrations of TP recorded in $V 1$ and $V 3$ were 0.20 and $0.52 \mathrm{mg} / \mathrm{L}$, respectively. Across the entire operation period, TP showed no or only slight dependence on time in V1 and V2; however, TP steadily declined in $V 3$ and $V 4$, from 0.59 to $0.47 \mathrm{mg} / \mathrm{L}$ and from 0.77 to $0.62 \mathrm{mg} / \mathrm{L}$, respectively (Fig. 4a).

Variations in the concentrations of TDP (Fig. 4b) and SRP (Fig. 4c) in the effluent are similar to the variations in TP. However, the percentage of SRP in TDP (SRP/TDP) in the effluent fluctuated considerably (Fig. 4d). SRP is one of the sources of phosphorus that is immediately available for biological uptake, and a high concentration of SRP results in the eutrophication of water [22]. The percentage of SRP/TP in the effluent was the highest in $V 1$, reaching $80 \%$ on average, whereas, the lowest was measured in $V 2$ with an average of $70 \%$. The mean percentages for SRP/TP were 76 and $78 \%$ in $V 3$ and $\mathrm{V} 4$, respectively.

The concentrations of PP in the effluent were very different in each of the simulated riparian zones (Fig. 4e). The PP concentration ranged from 0.06 to $0.07 \mathrm{mg} / \mathrm{L}$ in $V 1$, from 0.07 to $0.08 \mathrm{mg} / \mathrm{L}$ in $V 2$, from 0.19 to $0.29 \mathrm{mg} / \mathrm{L}$ in $V 3$, and from 0.31 to $0.41 \mathrm{mg} / \mathrm{L}$ in $V 4$. The average concentration of PP in the effluent from $V 1$ was $0.06 \mathrm{mg} / \mathrm{L}$, and demonstrated little dependence on time during the experimental process. The highest concentration of $\mathrm{PP}$ was measured in V4, with an average 

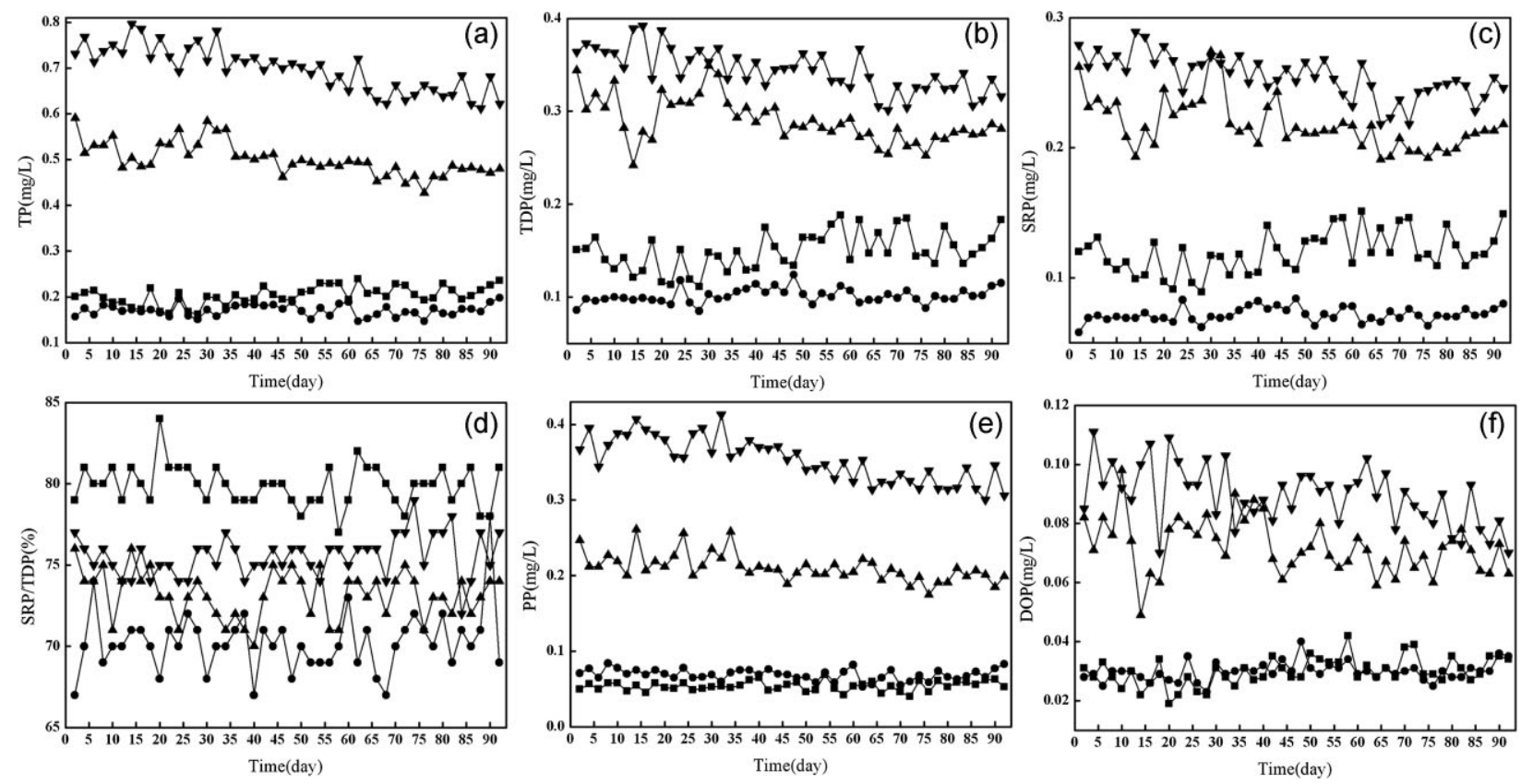

Figure 4. Phosphorus speciation in the effluent from simulated riparian zones with $P$. ryegrass. $V 1$, filled squares; $V 2$, filled circles; V3, filled up-triangles; V4, filled down-triangles.

of $0.35 \mathrm{mg} / \mathrm{L}$. As time passed, the PP concentration declined, similar to the concentration of TP in V3 and V4. PP provides a potential source of phosphorus for the growth of aquatic plants, and PP leads to less eutrophication in natural waters compared with SRP [22].

In $V 1$ and $V 2$, the DOP concentrations of the effluent kept relatively constant with averages of 0.05 and $0.03 \mathrm{mg} / \mathrm{L}$, respectively (Fig. 4f). However, the DOP content of the effluent from V3 and V4 fluctuated dramatically across the entire experimental period. In $V 3$, the concentration of DOP ranged from 0.06 to $0.08 \mathrm{mg} / \mathrm{L}$. In $\mathrm{V} 4$, the content of DOP ranged from 0.07 to $0.11 \mathrm{mg} / \mathrm{L}$. DOP is also considered a readily available source of phosphorus for aquatic organisms. DOP more readily results in the eutrophication of water bodies compared with PP because it can be converted into nutrients through enzymatic hydrolysis, especially when the concentration of SRP is low [23].

Under uniform conditions, such as the simulated system employed here, influent concentration, humidity, temperature, etc., the addition ratio of RM significantly affect the removal efficiency of phosphorus from reclaimed water $(F[\mathrm{~d} f=3]=91.06$; $p<0.01)$. These results suggest that the best proportion of RM is around $2.5 \%$ by weight (V2) for the removal of phosphorus from reclaimed water, as this proportion resulted in the lowest concentrations of TP, TDP, SRP, SRP/TP, and DOP in the effluent and the removal efficiency showed little dependence on operational time. Metal ion concentrations in the effluent of V2 were as follows (in $\mathrm{mg} / \mathrm{L})$ : $\mathrm{Fe}(0.56 \pm 0.12)$, $\mathrm{Cu}(0.38 \pm 0.21)$, and $\mathrm{Al}(0.60 \pm 0.18)$. The concentrations of other metal ions were too low to be detected, which satisfies landscape water quality standards for concentrations of metals in reclaimed water (GB/T 18921-2002).

\subsection{Phosphorus fractionation in the media}

The concentration and percentage composition of phosphorus in the media that received different addition ratios of RM are shown in Fig. 5. In general, the TP content of the media ranged from 480 to
$500 \mathrm{mg} / \mathrm{kg}$ before the systems received reclaimed water, including $\mathrm{V} 4$ which had the highest average concentration of $498 \mathrm{mg} / \mathrm{kg}$, whereas, $V 1$ and $V 2$ had the lowest average concentrations at 480 and $484 \mathrm{mg} / \mathrm{kg}$, respectively. This indicates that $V 1$ and $V 2$ had strong phosphorus adsorption abilities based on the lower TP content in these media. After treating the reclaimed water, the average increase in the TP contents of $V 1, V 2, V 3$, and $V 4$ were $80,102,55$, and $29 \mathrm{mg} / \mathrm{kg}$, respectively (Fig. 5a). In the present study, the amount of TP removed by the media accounted for $81 \%$ of the TP removed in V2. Therefore, phosphorus removal is mainly caused by physical, chemical, and biological interactions in the media, which is consistent with the results of previous studies [24, 25].

$\mathrm{Ca}-\mathrm{P}$, which is extracted by $\mathrm{HCl}$, is the form of phosphorus associated with calcium minerals. Ca-P is generally unavailable for biological assimilation [26]. Ca-P was the dominant fraction found in the different simulated riparian zones, both before and after the zones received reclaimed water (Fig. 5). High $\mathrm{pH}$ values that are usually associated with high calcium levels in the media induced the phosphorus in the reclaimed water to form $\mathrm{Ca}-\mathrm{P}$ in large quantities. Before this study was conducted, the highest content of $\mathrm{Ca}-\mathrm{P}$ was measured in $\mathrm{V} 4$, reaching $259 \mathrm{mg} / \mathrm{kg}$ on average and accounting for $52 \%$ of TP; the lowest content was found in $V 1$ with an average of $231 \mathrm{mg} / \mathrm{kg}$ and $48 \%$ of TP. After the study, the mean content of Ca-P from $\mathrm{V} 2$ was the highest at $342 \mathrm{mg} / \mathrm{kg}$ and $58 \%$ of $\mathrm{TP}$; the lowest content was measured in $V 1$ with an average concentration of $281 \mathrm{mg} / \mathrm{kg}$ and $50 \%$ of TP.

$\mathrm{NaOH}$-extracted phosphorus contains inorganic $(\mathrm{Al} / \mathrm{Fe}-\mathrm{P})$ and organic (Org-P). Al/Fe-P represents the phosphorus associated with iron and aluminum oxides, which is the dominant form of inorganic phosphorus especially when a phosphorus deficit occurs [27, 28]. Org$\mathrm{P}$ represents the organic phosphorus associated with humic and fulvic acids which is considered to be resistant to biological decomposition [29]. Before this study, the mean concentration of $\mathrm{Al} / \mathrm{Fe}-\mathrm{P}$ in $\mathrm{V} 1$ was the highest, which was measured at $106 \mathrm{mg} / \mathrm{kg}$, 
(a) A/Fe-P $_{\text {A }}$ Ca-P
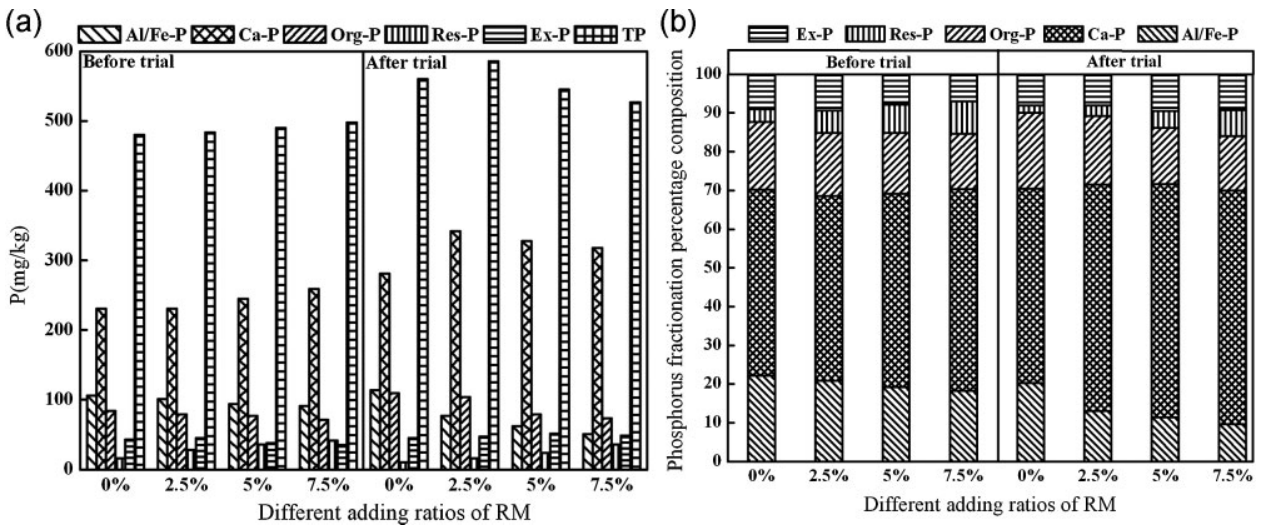

Figure 5. Concentrations (a) and percentage compositions (b) of phosphorus fractions in the media of the four simulated riparian zones, before and after the study.

whereas, the lowest concentrations were measured in V3 and V4 with average concentrations of 94 and $92 \mathrm{mg} / \mathrm{kg}$, respectively. However, at the end of the study, the average concentration of $\mathrm{Al} / \mathrm{Fe}-\mathrm{P}$ in $\mathrm{V} 1$ increased by $7 \mathrm{mg} / \mathrm{kg}$, whereas, the $\mathrm{Al} / \mathrm{Fe}-\mathrm{P}$ concentration declined by 25,32 , and $40 \mathrm{mg} / \mathrm{kg}$ in $V 2, V 3$, and $V 4$, respectively (Fig. 5). The mean concentrations of Org-P in V1, V2, V3, and V4 increased from 84 to $110 \mathrm{mg} / \mathrm{kg}$, from 79 to $103 \mathrm{mg} / \mathrm{kg}$, from 76 to $80 \mathrm{mg} / \mathrm{kg}$, and from 71 to $74 \mathrm{mg} / \mathrm{kg}$ after the reclaimed water was fed, respectively.

Phosphorus, which is extracted by $\mathrm{KCl}$, represents the labile pool of Ex-P. Ex-P is the most chemically reactive element which would be responsible for controlling the phosphorus concentration of natural waters [30]. Ex-P, which was measured at concentrations of less than $50 \mathrm{mg} / \mathrm{kg}$, was comparatively low in all of the simulated systems and independent of the addition ratios of RM (Fig. 5a). Res-P was not extracted by $\mathrm{KCl}, \mathrm{NaOH}$, or $\mathrm{HCl}$, which is considered to be a refractory organic phosphorus fraction and biologically unavailable [31]. The mean concentration of Res-P, which was never measured above the concentration of $40 \mathrm{mg} / \mathrm{kg}$, was the lowest phosphorus fraction. Furthermore, Res-P remained at a stable level, and showed less dependence on the addition ratio of RM.

A significant correlation was found between the TP content in the effluent and the concentration of extractable calcium of the media $(p<0.05)$. An extremely significant relationship was observed between extractable calcium and $\mathrm{Ca}-\mathrm{P}$ concentrations in the media $(p<0.01)$. These significant correlations suggest that phosphorus adsorption and precipitation in the media are associated with the concentrations of the poorly crystalline forms of calcium. Moreover, the $\mathrm{Ca}-\mathrm{P}$ fraction was positively correlated with the amount of RM added to the media, whereas, $\mathrm{Al} / \mathrm{Fe}-\mathrm{P}$ was negatively correlated. Consequently, the addition of RM to the media contributed to the conversion of $\mathrm{Al} / \mathrm{Fe}-\mathrm{P}$, which is strongly bioactive, to $\mathrm{Ca}-\mathrm{P}$, which is much more stable. This could further reduce the release of phosphorus from the media and lower the amount of eutrophication that occurs in water.

\subsection{Phosphorus accumulation in plants}

In this study, P. ryegrass thrived in $V 1$ and attained an average height of $25 \mathrm{~cm}$. Although $P$. ryegrass was able to grow in $V 2$, the high $\mathrm{pH}$ affected its growth, resulting in dead leaves on some plants and an average height of $23 \mathrm{~cm}$. The survival rate of $P$. ryegrass in $V 3$ was around $20 \%$, with an average height of just $12 \mathrm{~cm}$. Most of the $P$. ryegrass in $V 4$ did not survive.

The effect of $P$. ryegrass on the concentration of phosphorus speciation is shown in Fig. 6 . In 1 and 2 the ordination results show a clear separation between simulated systems that did or did not have plants. In 1, which did not receive an addition of RM, the system without plants were predominantly located in the first and second quadrants, whereas, those systems with plants were predominantly distributed throughout the other two quadrants. In 2 , the addition of $2.5 \% \mathrm{RM}$ resulted in the system without plants being located mainly in the second and third quadrants, whereas, the system with plants was predominantly located in the fourth quadrant. In $V 1$ and $V 2$, the concentrations of phosphorus speciation in the effluent were positively correlated with the non-plant systems, but negatively correlated with the plant systems, indicating that plants play an active role in the removal of phosphorus. However, the ordination results obtained by PCA in 3 with 5\% RM and 4 with $7.5 \%$ RM do not distinguish between phosphorus content in response to the systems with or without plants, as the phosphorus concentration spread out throughout each quadrant. In addition, no correlation could be determined between the concentrations of various forms of phosphorus in the effluent and the presence of plants in each system.

This study shows that plants do not have a critical effect on the removal of phosphorus from riparian zones, which was supported by some researches $[32,33]$. The systems with plants $(V)$ had slightly higher phosphorus removal efficiencies than those without plants (C). TP removal from $V 1$ was $5 \%$ higher than that of a similar system without plants $(C 1)$, and the TP storage in plants was $1.86 \mathrm{~g}$. Analysis by one-way ANOVA showed that the concentrations of phosphorus speciation in the effluent from $C 1$ were slightly, but not significantly, lower than $V 1(p>0.05)$. Compared with V2, TP removal was $4 \%$ lower in $C 2$ and TP storage in plants was $1.57 \mathrm{~g}$. Similarly, the results of the one-way ANOVA analysis indicate that plants did not have a significant effect on phosphorus speciation removal from reclaimed water $(p>0.05)$. TP removal in C3 was slightly lower than that in V3, and TP storage in plants was just $0.75 \mathrm{~g}$, and the statistical analysis shows that plants did not play a significant role in the removal of phosphorus species $(p>0.05)$. However, when the RM content was $7.5 \%$, the phosphorus removal efficiency of the system with plants (i.e., V4) was slightly lower than that of the system without plants (i.e., C4), which might have resulted from the stored nutrients in the plants to be rapidly released into the water column during the decomposition 

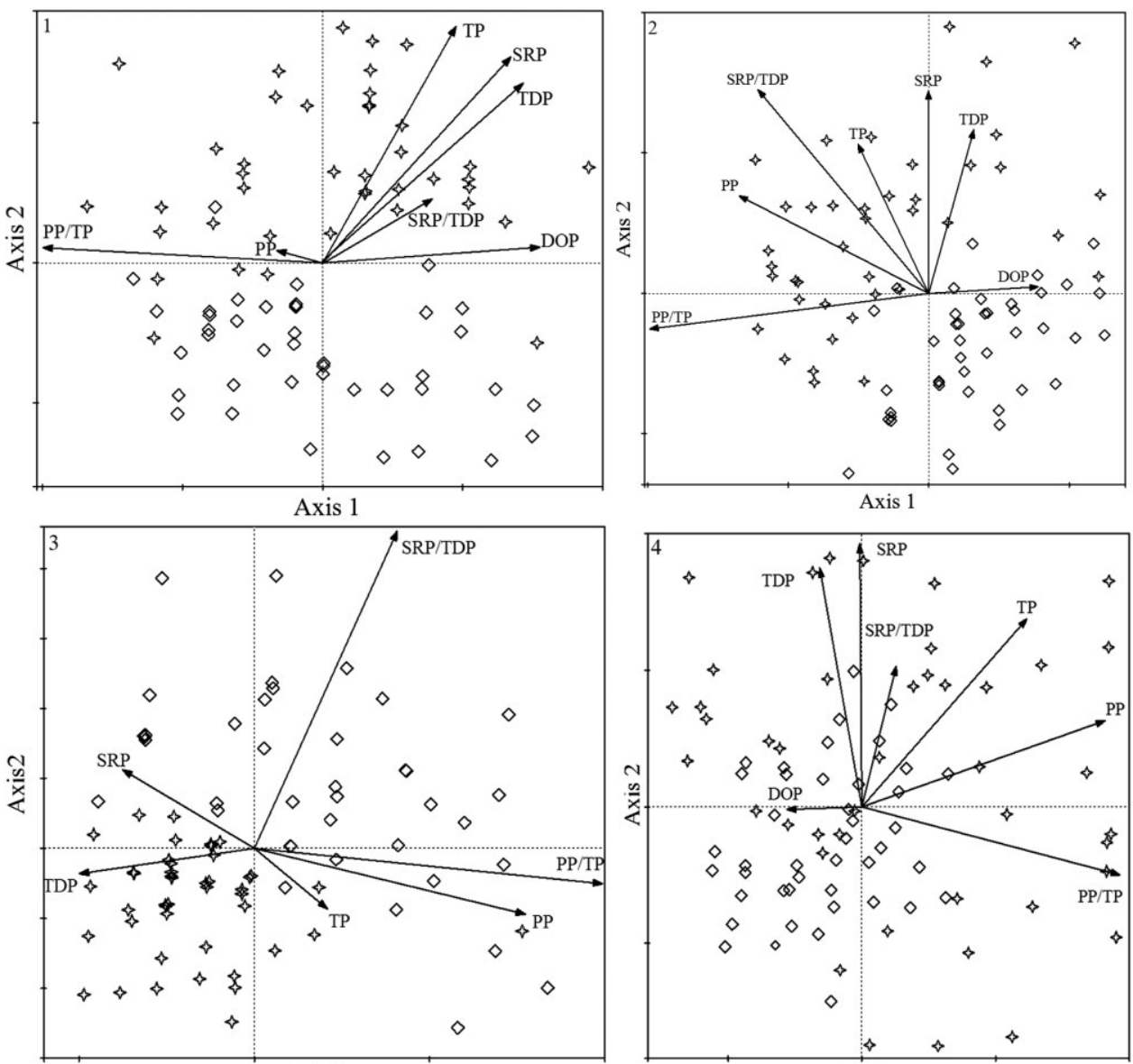

Axis 1

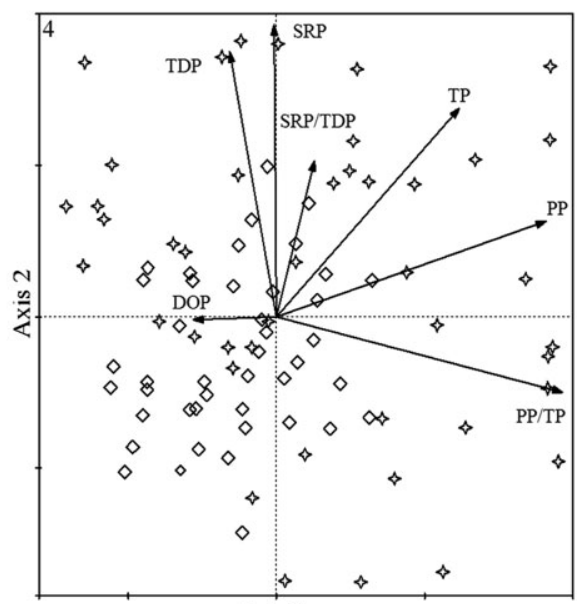

Axis 1

Figure 6. Ordination diagram of four simulated riparian zones showing the role of plants on phosphorus removal from reclaimed water by PCA. With $P$. ryegrass: open stars; without $P$. ryegrass: open diamonds.

of detrital tissue following the death of most of the P. ryegrass plants. The role of plants on phosphorus removal decreased with increasing amounts of RM, as the plants were able to take up the monovalent form of $\mathrm{HPO}_{4}^{-}$from the water column, however, when the $\mathrm{pH}$ is $>7.2$, most phosphorus tends to be present in the forms of $\mathrm{HPO}_{4}^{2-}$ and $\mathrm{PO}_{4}^{3-}$, which are difficult forms for plants to utilize [20, 34].

\section{Concluding remarks}

RM contains a large proportion of voids that are evenly distributed, a fine particle size, and a high calcium content of about $26.62 \%$ of its weight. The best proportion of RM was determined to be approximately $2.5 \%$ by weight, which showed an outstanding capacity for phosphorus species removal from reclaimed water. When the RM content is $2.5 \%$ by weight, this optimal $\mathrm{pH}$ range, the presence of $\mathrm{HPO}_{4}^{2-}$ and $\mathrm{PO}_{4}^{3-}$, and a suitable concentration of calcium in the media improved the removal of phosphorus through the adsorption of media and the assimilation of P. ryegrass in the simulated riparian zones. Moreover, the reasonable addition of $2.5 \% \mathrm{RM}$ to the media contributed to the conversion of $\mathrm{Al} / \mathrm{Fe}-\mathrm{P}$ (which has an intense bioactivity) to $\mathrm{Ca}-\mathrm{P}$ (which is more stable), thereby, decreasing the risk of phosphorus being released from the media.

Clearly, RM can be directly used in riparian zones as a novel and low cost material to enhance the removal of phosphorus from reclaimed water in China.

\section{Acknowledgments}

This research was supported by the National Basic Research Program of China (No. 2006CB403306) and Special Foundation for Science and Technology Innovation of Tianjin (No.06FZZDSH00900).

The authors have declared no conflicts of interest.

\section{References}

[1] F. Kehagia, A Successful Pilot Project Demonstrating the Re-Use Potential of Bauxite Residue in Embankment Construction, Resour. Conserv. Recycl. 2010, 54 (7), 417.

[2] C. Brunori, C. Cremisini, P. Massanisso, V. Pinto, L. Torricelli, Reuse of a Treated Ted Mud Bauxite Waste: Studies on Environmental Compatibility, J. Hazard. Mater. 2005, 117 (1), 55.

[3] S. Sushil, V. S. Batra, Catalytic Applications of Red Mud, an Aluminum Industry Waste: A Review, Appl. Catal., B 2008, 81 (1-2), 64.

[4] Y. Cengeloglu, A. Tor, M. Ersoz, G. Arslan, Removal of Nitrate from Aqueous Solution by Using Red Mud, Sep. Purif. Technol. 2006, 51 (3), 374.

[5] C. W. Gray, S. J. Dunham, P. G. Dennis, F. J. Zhao, S. P. McGrath, Field Evaluation of In Situ Remediation of a Heavy Metal Contaminated Soil Using Lime and Red-mud, Environ. Pollut. 2006, 142 (3), 530.

[6] D. I. Smirnov, T. V. Molchanova, The Investigation of Sulphuric Acid Sorption Recovery of Scandium and Uranium from the Red Mud of Alumina Production, Hydrometallurgy 1997, 45 (3), 249. 
[7] K. R. Mankin, D. M. Ngandu, C. J. Barden, S. L. Hutchinson, W. A. Geyer, Grass-Shrub Riparian Buffer Removal of Sediment, Phosphorus, and Nitrogen from Simulated Runoff, J. Am. Water Resour. Assoc. 2007, 43 (5), 1108.

[8] E. Struyf, W. Kotowski, S. Jacobs, S. V. Damme, K. Bal, W. Opdekamp, $\mathrm{H}$. Backx, et al., Tracing Si-N-P Ecosystem-Pathways: Is Relative Uptake in Riparian Vegetation Influenced by Soil Water Logging, Mowing Management and Species Diversity?, Hydrobiologia 2011 674 (1), 41.

[9] X. Y. Zhang, X. M. Liu, M. H. Zhang, R. A. Dahlgren, A Review of Vegetated Buffers and a Meta-Analysis of Their Mitigation Efficacy in Reducing Nonpoint Source Pollution, J. Environ. Qual. 2010, 39 (1), 76.

[10] K. R. Reddy, R. H. Kadlec, E. Flaig, P. M. Gale, Phosphorus Retention in Streams and Wetlands: A Review, Crit. Rev. Environ. Sci. Technol. 1999, 29 (1), 83.

[11] B. Q. Shan, C. M. Hu, W. Z. Tang, Y. J. Cheng, Variations in Phosphorus Speciation in Pilot Scale Subsurface Flow Wetlands Constructed with Blast Furnace Slag and Gravel, Clean - Soil Air Water 2009, 37 (10), 818.

[12] J. P. Coelho, M. R. Flindt, H. S. Jensen, A. I. Lillebø, M. A. Pardal, Phosphorus Speciation and Availability in Intertidal Sediments of a Temperate Estuary: Relation to Eutrophication and Annual P-fluxes, Estuar. Coast. Shelf Sci. 2004, 61 (4), 583.

[13] SEPAC (State Environmental Protection Administration of China), Methods for Examination of Water and Wastewater, China Environmental Science Press, Beijing 2002

[14] S. D. Bao, Chemical Analysis for Agricultural Soil, China Agriculture Press, Beijing 2000.

[15] A. Moore, K. R. Reddy, Role of Eh and $\mathrm{pH}$ on Phosphorus Geochemistry in Sediments of Lake Okeechobee, Florida, J. Environ. Qual. 1993, 23 (5), 955.

[16] H. L. Zhang, J. L. Kovar, Fractionation of Soil Phosphorus, in Methods of Phosphorus Analysis for Soils, Sediments, Residuals, and Waters (Ed.: G. M. Pierzynski), Southern Cooperative Series Bulletin No. 396, North Carolina State University, Raleigh, NC 2009, p. 50-60.

[17] D. Steffens, T. Leppin, N. L. Ebengreuth, Z. M. Yang, S. Schubert, Organic Soil Phosphorus Considerably Contributes to Plant Nutrition but is Neglected by Routine Soil-Testing Methods, J. Plant Nutr. Soil Sci. 2010, 173 (5), 765.

[18] L. Johansson, J. P. Gustafsson, Phosphate Removal Using Blast Furnace Slags and Opoka-Mechanisms, Water Res. 2000, 34 (1), 259.

[19] C. J. Richardson, Mechanisms Controlling Phosphorus Retention Capacity in Freshwater Wetlands, Science 1985, 228 (4706), 1424.

[20] E. Oguz, Removal of Phosphate from Aqueous Solution with Blast Furnace Slag, J. Hazard. Mater. 2004, 114 (1-3), 131.
[21] D. P. Schachtman, R. J. Reid, S. M. Ayling, Phosphorus Uptake by Plants: From Soil to Cell, Plant Physiol. 1998, 116 (2), 447.

[22] D. M. Karl, G. Tien, J. Dore, C. D. Winn, Total Dissolved Nitrogen and Phosphorus Concentrations at US-JGOFS Station ALOHA: Redfield Reconciliation, Mar. Chem. 1993, 41 (1-3), 203.

[23] G. W. Zhu, B. Q. Qin, L. Zhang, L. C. Luo, Geochemical Forms of Phosphorus in Sediments of Three Large, Shallow Lakes of China, Pedosphere 2006, 16 (6), 726.

[24] M. Sundaravadivel, S. Vigneswaran, Constructed Wetlands for Wastewater Treatment, Crit. Rev. Environ. Sci. Technol. 2001, 31 (4), 341.

[25] A. K. Ghosh, J. Barbosa, I. R. Silva, An Environmental Threshold of Soil Test P and Degree of P Saturation of Brazilian Oxisols, Clean Soil Air Water 2011, 39 (5), 421.

[26] H. L. Liu, C. Q. Yin, H. J. Wang, W. D. Wang, B. Q. Shan, Sedimentary Phosphorus Form Distribution and Cycling in the Littoral Subzones of an Eutrophic Lake, Clean - Soil Air Water 2008, 36 (1), 78.

[27] M. A. Beck, P. A. Sanchez, Soil Phosphorus Fraction Dynamics during 18 Years of Cultivation on a Typic Paleudult, Soil Sci. Soc. Am. J. 1994, 58 (5), 1424

[28] J. E. Richards, T. E. Bates, S. C. Sheppard, Changes in the Forms and Distribution of Soil Phosphorus due to Long-Term Corn Production, Can. J. Soil. Sci. 1995, 75 (3), 311.

[29] T. Q. Zhang, A. F. MacKenzie, Changes of Phosphorus Fractions under Continuous Corn Production in a Temperate Clay Soil, Plant Soil 1997, 192 (1), 133.

[30] K. R. Reddy, O. A. Diaz, L. J. Scinto, M. Agami, Phosphorus Dynamics in Selected Wetlands and Streams of the Lake Okeechobee Basin, Ecol. Eng. 1995, 5 (2-3), 183.

[31] H. Zhang, B. Q. Shan, Historical Distribution and Partitioning of Phosphorus in Sediments in an Agricultural Watershed in the Yangtze-Huaihe Region, China, Environ. Sci. Technol. 2008, 42 (7), 2328.

[32] D. G. Guo, Z. K. Bai, T. L. Shangguan, H. B. Shao, W. Qiu, Impacts of Coal Mining on the Aboveground Vegetation and Soil Quality: A Case Study of Qinxin Coal Mine in Shanxi Province, China, CleanSoil Air Water 2011, 39 (3), 219

[33] K. Hüve, W. Merbach, R. Remus, D. Lüttschwager, L. Wittenmayer, K Hertel, U. Schurr, Transport of Phosphorus in Leaf Veins of Vicia faba L., J. Plant Nutr. Soil Sci. 2007, 170 (1), 14.

[34] C. M. Hu, B. Q. Shan, Phosphorus Removal Performance and Mechanisms of a Constructed Horizontal Subsurface Flow Wetlands Treating Reclaimed Water, Environ. Eng. Sci. 2009, 26 (6), 1097-1106. 